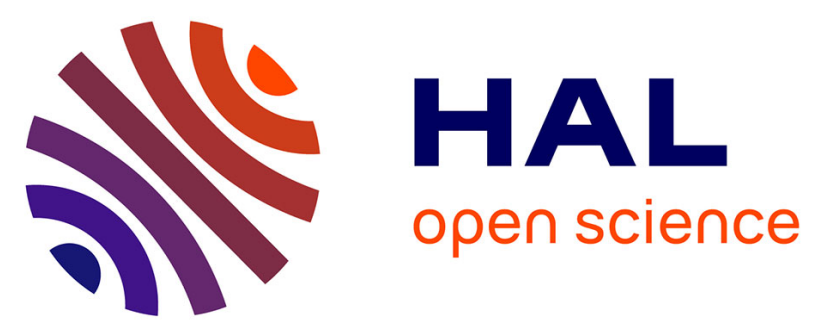

\title{
Comparison of different surface treatments of carbon fibers used as reinforcements in epoxy composites: Interfacial strength measurements by in-situ scanning electron microscope tensile tests
}

Yu Liu, Delong He, Ann-Lenaig Hamon, Benhui Fan, Paul Haghi-Ashtiani, Thomas Reiss, Jinbo Bai

\section{To cite this version:}

Yu Liu, Delong He, Ann-Lenaig Hamon, Benhui Fan, Paul Haghi-Ashtiani, et al.. Comparison of different surface treatments of carbon fibers used as reinforcements in epoxy composites: Interfacial strength measurements by in-situ scanning electron microscope tensile tests. Composites Science and Technology, 2018, 167, pp.331-338. 10.1016/j.compscitech.2018.08.018 . hal-01960228

\section{HAL Id: hal-01960228}

https://hal-centralesupelec.archives-ouvertes.fr/hal-01960228

Submitted on 20 Apr 2020

HAL is a multi-disciplinary open access archive for the deposit and dissemination of scientific research documents, whether they are published or not. The documents may come from teaching and research institutions in France or abroad, or from public or private research centers.
L'archive ouverte pluridisciplinaire HAL, est destinée au dépôt et à la diffusion de documents scientifiques de niveau recherche, publiés ou non, émanant des établissements d'enseignement et de recherche français ou étrangers, des laboratoires publics ou privés. 


\title{
Comparison of different surface treatments of carbon fibres used as reinforcements in epoxy composites: Interfacial strength measurements by in-situ scanning electron microscope tensile tests
}

Yu LIU, Delong HE*, Ann-Lenaig HAMON, Benhui FAN, Paul HAGHI-ASHTIANI, Thomas REISS and Jinbo BAI*

Laboratoire Mécanique des Sols, Structures et Matériaux (MSSMat), CNRS UMR 8579, CentraleSupélec, Université Paris-Saclay, 3 rue Joliot-Curie, 91192 Gif-sur-Yvette Cedex, France

Corresponding email: jinbo.bai@centralesupelec.fr, delong.he@ centralesupelec.fr

KEYWORDS: Interface strength, Interphase, FIB, STEM, EDX, fibers/Epoxy composites

\begin{abstract}
In this study, the interfacial strength of carbon fibre (CF)/epoxy composites was measured insitu in a scanning electron microscope (SEM). To investigate the relationship between the surface of a $\mathrm{CF}$ and the interfacial strength, four kinds of $\mathrm{CF}$-raw $\mathrm{CF}$, desized $\mathrm{CF}$, carbon nanotubes grafted CF (CF-CNTs) and oxidized CF-CNTs-were used to prepare epoxy composites. A sample containing part-CF and part-epoxy matrix was used to perform in-situ tensile tests in a SEM. The fracture strains of raw CF/epoxy, desized CF/epoxy, CFCNTs/epoxy and oxidized CF-CNTs/epoxy were clearly observed and the axial interfacial strength was also derived. The interfacial strength decreased from the initial value of $53 \mathrm{MPa}$ for the raw CF/epoxy to $48 \mathrm{MPa}$ for the desized CF/epoxy. However, by grafting CNTs on the $\mathrm{CF}$ surface, the interfacial strength of CF-CNTs/epoxy reached 55MPa and was further increased to $58 \mathrm{MPa}$ after the oxidation treatment. To understand the influence of interface modification, energy dispersion X-ray analysis (EDX) was carried out under scanning transmission electron microscopy (STEM). Based on the EDX mapping, it can be found that oxygen aggregated at the interfaces of raw CF/epoxy and oxidized CF-CNTs/epoxy, which indicates that the chemical bonding plays a crucial role in the enhancement of interfacial interactions.
\end{abstract}

*Corresponding author. E-mail: Jinbo.Bai@centralesupelec.fr (J. BAI); Delong.He@centralesupelec.fr (D. He) 


\section{INTRODUCTION}

The interface between fibres and matrix is considered to have a major influence on the mechanical properties of composites [1-4]. The good bonding or interaction at the interface is essential for achieving high shear and off-axis strength, since the stress exerted on the polymer matrix is transferred to fibres through the interface [5-8]. Increasing surface roughness and depositing transition layer are two major methods to improve the interfacial properties between polymer matrix and fibres. For instance, covering a sizing layer on fibre surface has proved to be an efficient method to enhance the interaction between CF and the polymer matrix $[9,10]$. In recent years, the introduction of carbon nanotubes (CNTs) into conventional continuous fibre-reinforced polymer to create hierarchical reinforced structures is a current topic of interest [11-19]. Due to their unique structures, outstanding strength and modulus, excellent electrical and thermal properties, CNTs have been exploited to improve mechanical and functional properties for the fibre-reinforced composites [20-24]. To seek an optimum interaction at the interface for hierarchical composites, it is important to evaluate the interfacial strength in different states of surface modification.

Over the last four decades, numerous works have been published to reveal the interfacial properties between CF and epoxy matrix. Single fibre filament composite tests [25], single fibre pull-out tests [26] and droplet methods [27] have been applied to various systems. A method has also been developed in which fibres are pushed out of the matrix rather than being pulled out [28]. Each of these methods attempts to consider the interfacial shear strength between fibres and matrix. Also, another procedure [29] determined the tensile strength of the fibre-matrix interface by embedding fibres perpendicularly to the loading axis through the thickness of bond-shape specimens and observed using scanning electron microscopy (SEM). The fibres with high interfacial adhesion were reported to reinforce the composite's longitudinal shear. Meanwhile, the transverse tensile strength and fracture surfaces with resin-coated fibres indicated the good fibre-matrix adhesion.

Here, we develop an in-situ measurement of the interfacial strength for CF/epoxy composites using a SEM and a nano-manipulator which applies the tensile loads on the samples. Four kinds $\mathrm{CF}$ of different surface state--raw $\mathrm{CF}$, Desized $\mathrm{CF}$, carbon nanotube grafted $\mathrm{CF}$ (CNTs-CF) and oxidized CNTs-CF--have been used to study the various interfaces in the composites. A lamella containing half-fibre and half-epoxy is prepared by a focused ion beam (FIB) where the fibre is perpendicular to the tension axis, along the width of the 
specimen. This allows both an observation of the fracture behaviour of the interface and a measurement of its interfacial strength. Furthermore, an elemental analysis has been carried out in a scanning transmission electron microscopy (STEM) by combining an energy dispersive X-ray analysis (EDX) mapping which offers some insight into the effectiveness of the surface modification of the $\mathrm{CF}$.

\section{EXPERIMENTS}

\subsection{Materials preparation}

The growth of CNTs on CFs was carried out in a chemical vapor deposition (CVD) quartz tube with a diameter of $100 \mathrm{~mm}$, which was heated by an electrical resistance furnace (CARBOLITE®). One kind of T700 grade CF fabric was used in this study. Its diameter was around $7 \mu \mathrm{m}$. The furnace was heated up to $600{ }^{\circ} \mathrm{C}$ in an argon and hydrogen flow with a rate of 1.2 and $0.3 \mathrm{~L} / \mathrm{min}$, respectively. After $10 \mathrm{~min}$ stabilization, a xylene solution containing 0.1 $\mathrm{g} / \mathrm{ml}$ ferrocene was injected in form of spray into the reactor by a syringe injector, with an injection speed of $24 \mathrm{ml} / \mathrm{h}$. The growth lasted $3 \mathrm{~min}$ for CNTs grafted on the CFs. The furnace was finally cooled down to room temperature under argon protective atmosphere (1 $\mathrm{L} / \mathrm{min})[30]$.

The as-prepared CF-CNTs were subsequently oxidized: they were heated up to a temperature of $400{ }^{\circ} \mathrm{C}$ and stabilized for $4 \mathrm{~min}$ in air. Since the commercial CFs are coated by a sizing layer and since the influence of this layer is best studied by comparing with the rough CFs (without this layer), a "desizing process" has been conducted by heating the as-received CFs up to a temperature of $650^{\circ} \mathrm{C}$ for several minutes in an argon atmosphere.

A 1080 S epoxy resin (Resoltech, France), accompanied with the curing agent 1084 (Resoltech, France) with a mass ratio of $1 / 3$, was used. The resin and curing agent were mixed homogeneously and then a small bundle of CF fabric was slowly put into the epoxy matrix for a thorough immersion. Afterwards, the mixture was degassed for 60 min inside a vacuum oven at room temperature. The curing process was conducted at $60{ }^{\circ} \mathrm{C}$ for 15 hours. At last, the post-curing process was conducted at $100{ }^{\circ} \mathrm{C}$ for $1.5 \mathrm{~h}$. The as-prepared composites were cut into small cuboids for further microstructure characterizations.

\subsection{In-situ SEM tensile test}

$\mathrm{CF} /$ Epoxy composites used for the FIB-SEM was previously polished to obtain an ultra-smooth surface. The FIB sample preparation was performed in a Helios 660 (FEI) Dual 
Beam FIB-SEM system with a Ga+ ion source at $30 \mathrm{kV}$. The sample preparation procedures were showed in Fig.1. First, the cross-section with vertically aligned CF was selected (Fig. 1A) and the platinum $(\mathrm{Pt})$ protective layer with the thickness of $1.0 \mu \mathrm{m}$ was deposited on the surface of the target milling area (Fig.1B). To reduce the testing error, the Pt layer should cover the center of the target fiber, as shown in the insert scheme. Then, a $21 \mathrm{nA}$ and a $2.5 \mathrm{nA}$ beam current were applied respectively to obtain the lamella with a thickness of $\simeq 1.5 \mu \mathrm{m}$ (Fig.1C). Afterwards, the section was detached from the surrounding material and transferred to a TEM half-grid for fine thinning (Fig.1D). Then, fine thinning was carried out only at the stretching areas to remove the surface deposited materials. To avoid stress concentration during stretching, two quarter-circles were made in the CF region (Fig.1E). Finally, the micromanipulator was glued with the stretching sample by depositing a Pt layer. To avoid the point force loaded on the sample, the deposited Pt covered the whole width of the stretched sample (Fig.1F). The width and the thickness for the tested samples was $5.0 \mu \mathrm{m}$ and $1.5 \mu \mathrm{m}$, respectively and the epoxy part had a length ranging from $6.5 \mu \mathrm{m}$ to $7.0 \mu \mathrm{m}$.

Once the manipulator was bonded sturdy with the tensile sample by Pt deposition, the magnification of electron beam images and ion beam images were set properly, normally at $6500 \times$. The current of the ion beam was set to $80 \mathrm{pA}$ to decrease the damage to the tensile sample. A stepwise displacement of $200 \mathrm{~nm}$ was applied to the manipulator. Both electron beam image and ion beam image were acquired to measure the deformation during each tensile step.

All the tensile experiments were conducted following the same procedure, eight for raw CF/epoxy, five for desized CF/epoxy, five for CF-CNTs/epoxy and seven for oxidized CF-CNTs/epoxy, respectively. 

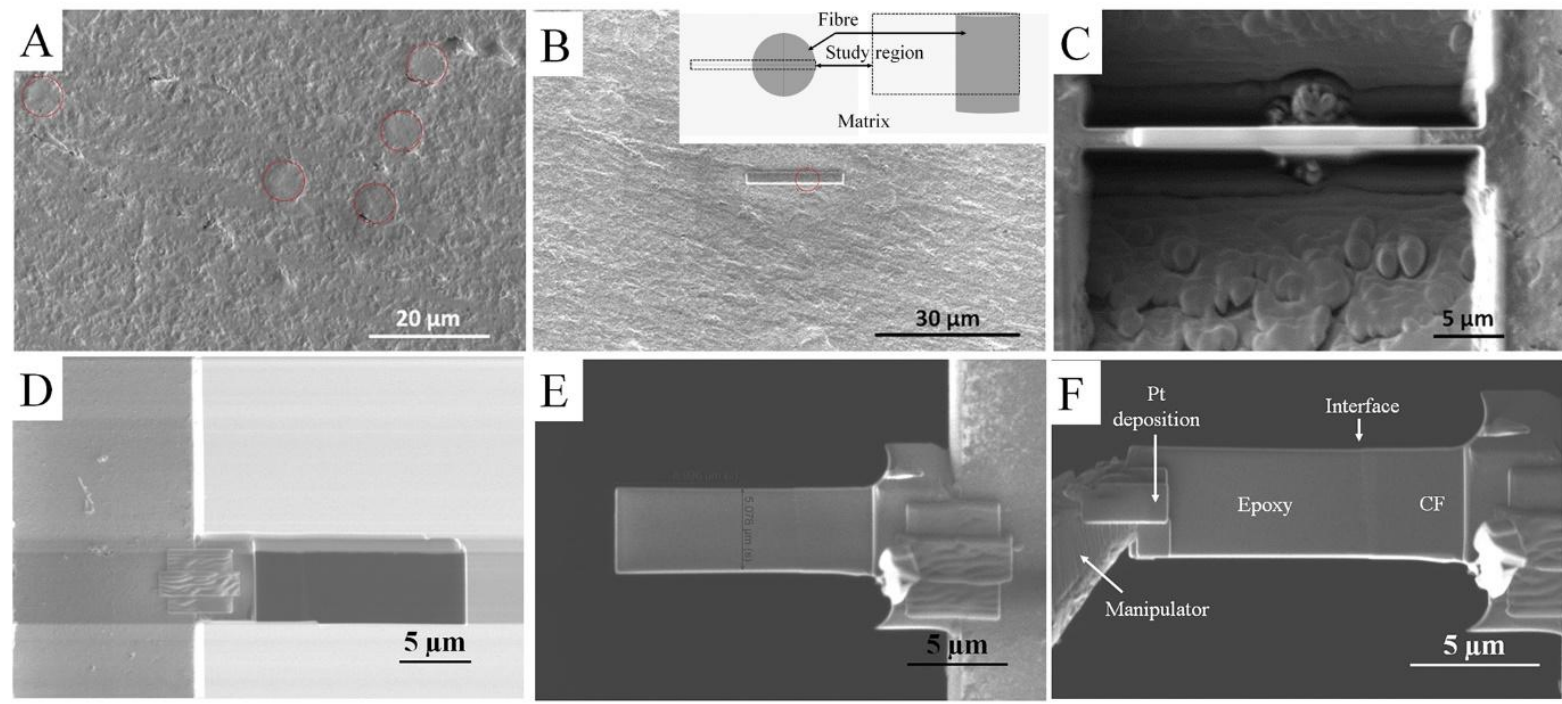

Fig. 1 The preparation of the sample for micro-tensile test: A) the polished surface containing several CF which are marked out by red circles; B) Pt protection is deposed on the CF/Epoxy interface with a dimension of $20 \mu \mathrm{m} \times 2 \mu \mathrm{m} \times 1 \mu \mathrm{m}$, and the red circle is for CF (The insert scheme shows the precise region where the tensile section was cut from); C) Tensile sample is milled to $1 \mu \mathrm{m}$ with a width of $8 \mu \mathrm{m}$; D) the lamella is lifted out by the manipulator and welded to the copper grid edge by Pt deposition; E) Two quarter-circles are conducted on the interface to avoid the stress concentration; F) The manipulator is attached to the lame by deposing Pt layer, the final stretching direction is vertical to the interface.

\subsection{Characterization}

The microstructure of different CF surfaces was observed by SEM (ZEISS, LEO 1530 Gemini) at $5 \mathrm{kV}$. The TEM sample preparation process was described in detail elsewhere [31]. TEM imaging was performed by a Titan3 G2 with a field emission gun (XFEG) operating at an accelerating voltage of $80 \mathrm{kV}$. Energy-dispersion X-ray microscopy (EDX) was carried out on the same equipment and operated at $80 \mathrm{kV}$ in a STEM mode. All the images were acquired by high-angle annular dark-field detector (HAADF). The EDX mapping was acquired for $10 \mathrm{~min}$.

\section{RESULTS and DISCUSSION}



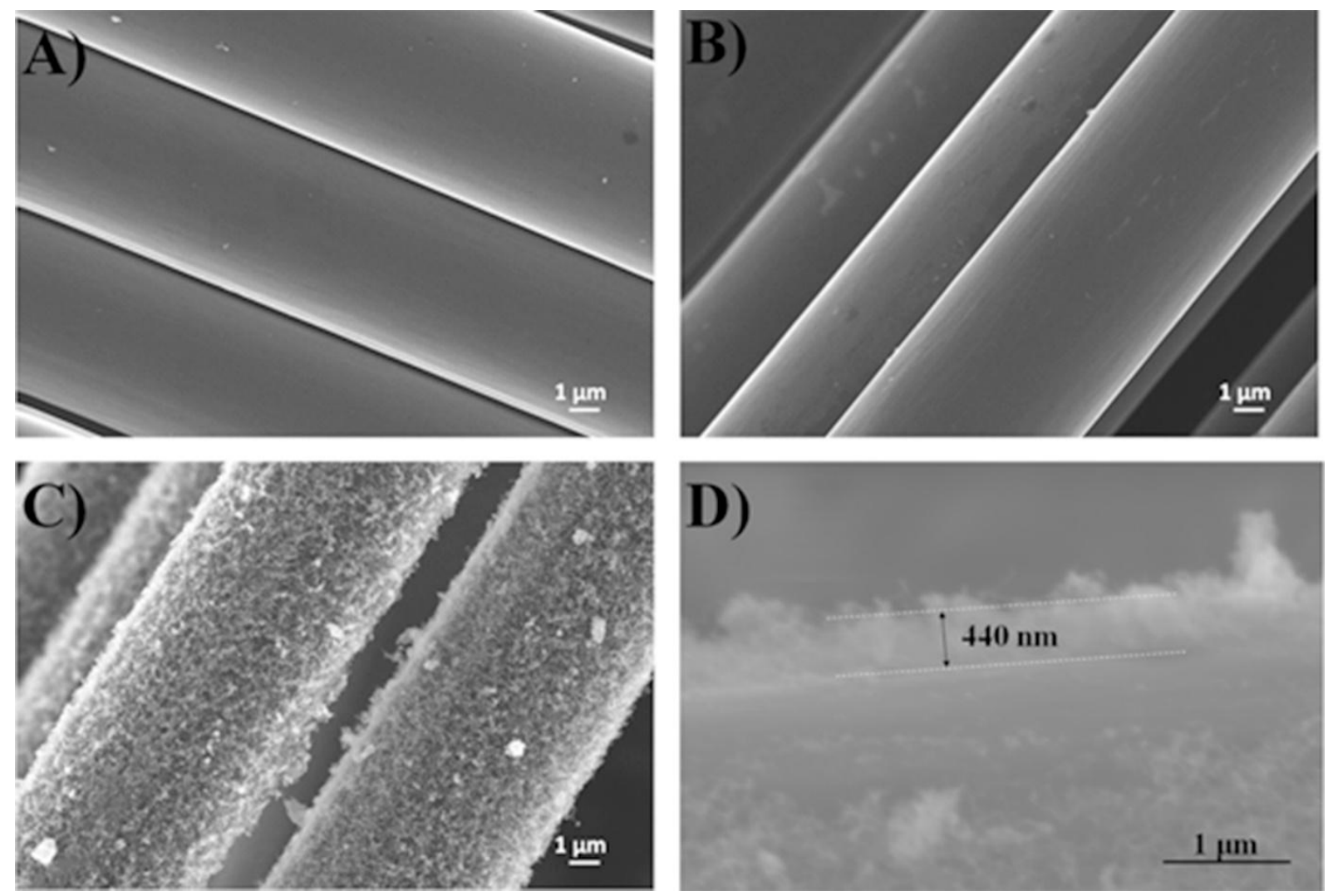

Fig. 2 SEM images showing the CF morphology: (A) original CFs; (B) desized CFs; (C) CNT-grafted CFs; and (D) CNT-CF to measure the thickness of the CNT layer.

The morphologies of the raw CFs, desized CFs and CF-CNTs are shown in Fig. 2. The raw fibres have a smooth and cylindrical surface with a diameter of around $7 \mu \mathrm{m}$ (Fig. 2A). After desizing, the CF surface has no obvious change and few difference could be detected at a SEM resolution scale (Fig. 2B). The in-situ growth of homogeneous CNTs on the CFs was achieved by an easy one-step CVD method using the metalorganic compound ferrocene as a catalyst precursor. As shown in Fig. 2C, the CNTs grow homogeneously on the whole surface of the fabric and on each CF. More importantly, each $\mathrm{CF}$ is covered by a continuous cylindrical shell consisting of aligned CNTs. The thickness of the CNT layer on the CF was measured by SEM, which can be seen in Fig. 2D. A part of the CNT was removed manually (i.e. using a macroscopic tool) before the SEM observation. The thickness of the CNT layer is about $440 \mathrm{~nm}$. The real thickness of the CNT layer may be larger than this value since the CF cylinder may not be tilted to the right position. To create some oxygen-containing groups on the $\mathrm{CF}$ and CNT surfaces, the CF-CNTs were heated up to a temperature of $400{ }^{\circ} \mathrm{C}$ in atmospheric condition for 3 min. No obvious change could be observed by SEM (Fig. S1B). 
To evaluate the axial interfacial strength between CFs and the epoxy matrix, an in-situ method has been developed in a SEM column. There are several advantages of testing fibres using in-situ SEM and a significant one among them is a precise measurement of the strain along the entire gauge length. Besides, the stretching process can be clearly observed along with the fracture behaviour.

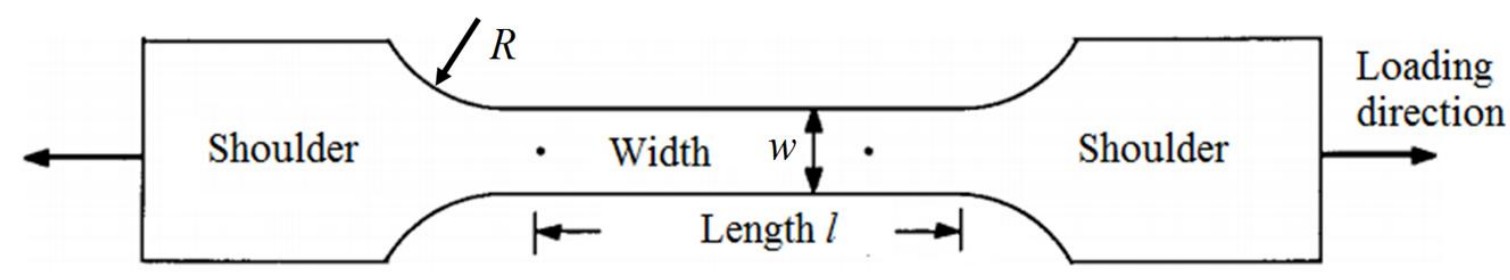

Fig. 3 Typical tensile specimen, showing a reduced gage section and enlarged shoulders.

Considering the typical tensile specimen in Fig. 3, it has enlarged ends or shoulders for griping. The important part of the specimen is the reduced gage section. The cross-sectional area of the gage section is reduced relative to that of the remainder of the specimen so that deformation and failure will be localized in this region. Another important area is the connection region between the gage section and the shoulders, which should be great enough so that the stress concentration do not affect the gage section. Usually, the R/W ratio is used to evaluate the stress concentration degree. In the traditional tensile test, this ratio is larger than 2 to avoid the stress concentration.
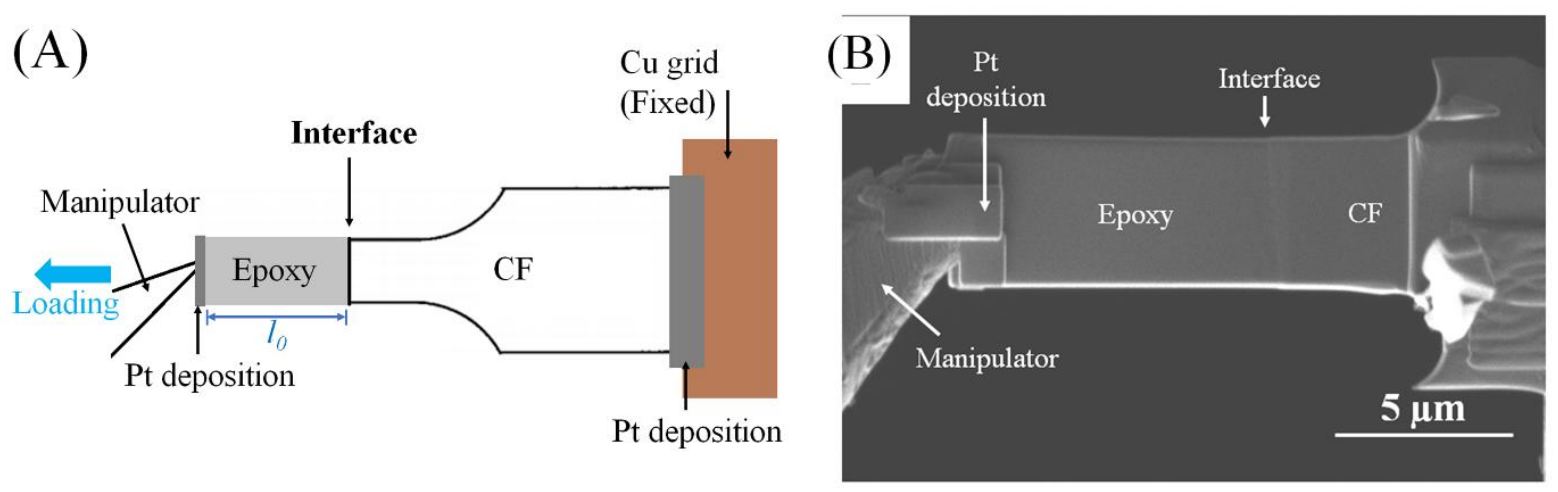

Fig. 4 The sketch of a tensile specimen to measure the interfacial strength between the CF and epoxy matrix; (B) SEM image of final tensile specimen prepared by FIB-SEM.

A specimen in micrometre-scale has been designed as shown in Fig. 4A. It keeps a half shape of traditional tensile specimen, with a gage section formed by the epoxy matrix and a shoulder section formed by the CF. To get rid of the stress concentration caused by the neck 
region, the interface moves far enough from it. The final specimen prepared by FIB is shown in Fig. 4(B). Theoretically, the stress transferred homogeneously in the cross-section all along the tensile specimen, the stress acting on the epoxy matrix equals the stress at the interface. Hence, the interfacial strength at the interface can be obtained by measuring the stress loading on the epoxy matrix part. Here are the details: (1) the original length (10) of epoxy matrix can be precisely measured on the SEM image from the interface to the edge of Pt deposition. (2) the tensile force is loaded by shifting the manipulator discontinuously with the smallest step (200 $\mathrm{nm}$ ) until the failure is reached. (3) the images are acquired after each shifting step to monitor length change in epoxy matrix.

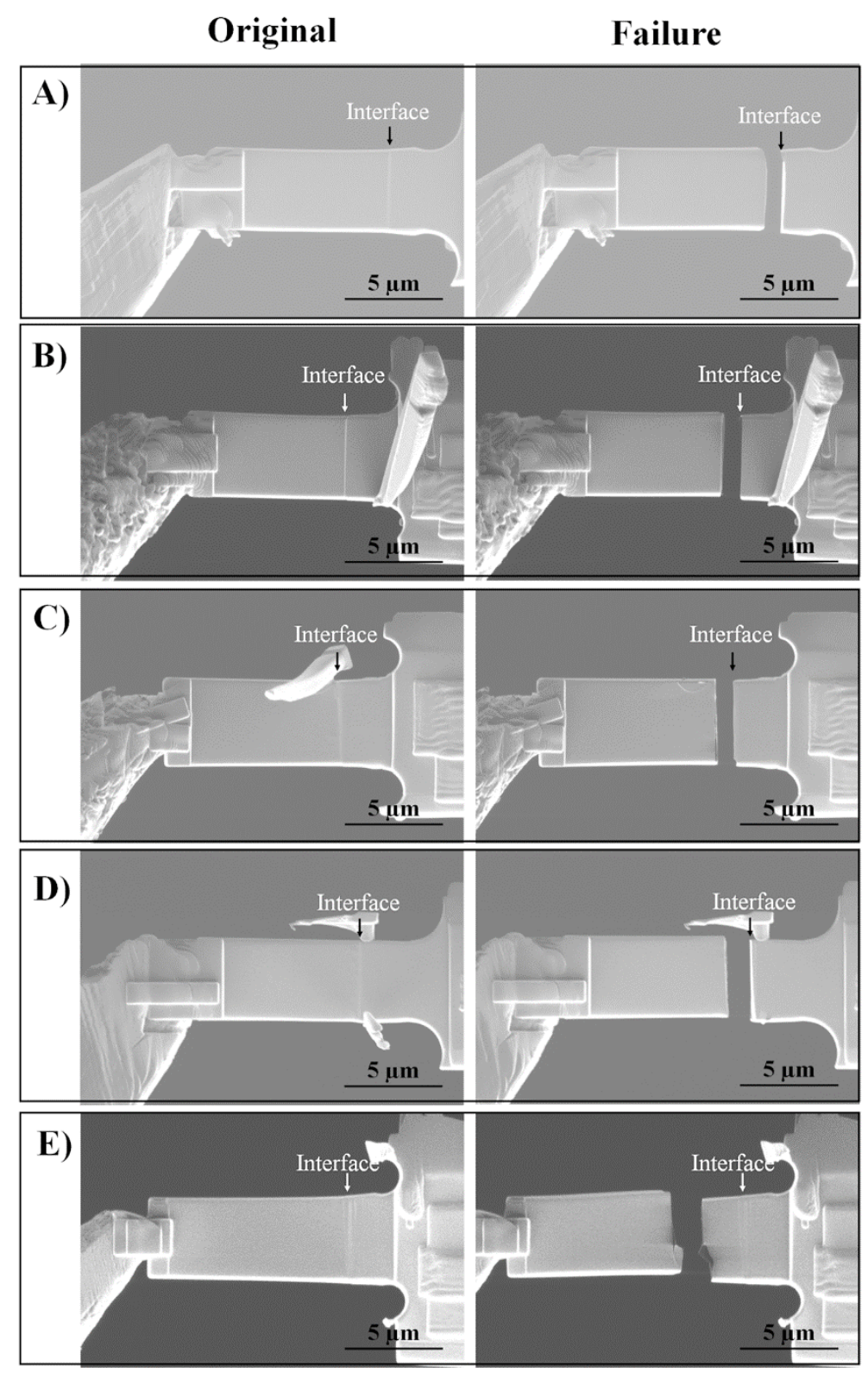


Fig. 5 Representative failure behavior for 4 different composites: (A) raw CF/epoxy, (B) desized CF/epoxy, (C) CNT-CF/epoxy, (D) oxidized CNT-CF/epoxy failure at the interface and (E) oxidized CNT-CF/epoxy failure in the epoxy matrix.

Fig. 5 provides the failure behavior for four different composites during the tensile test with the rectangular shape. Fig. 5(A) showed the raw CF/epoxy before and after failure, in which the fracture happened in the interface. By measuring the deformation on the matrix part, the interfacial stress could be estimated precisely. This situation happened in most part of tested samples of the desized CF (Fig. 5B), CNT-CF/epoxy (Fig. 5C) and oxidized CNTCF/epoxy composites (Fig. 5D). Fig. 5(E) shows a strong interaction in the interface, in which the fracture happens in the epoxy matrix. In this situation, the interfacial stress exceeds the fracture stress of epoxy matrix. This situation happened only in two tested samples of the oxidized CNT-CF/epoxy composites. Fig. S9(C) shows a failure tensile test due to the debonding of the manipulator. Usually, the epoxy matrix breaks in the plastic region. Hence, if the failure happens in the Pt deposition part, the specimen cannot be re-soldered since the second tensile in the failure sample could not reflect the real interfacial stress based on the strain.

A

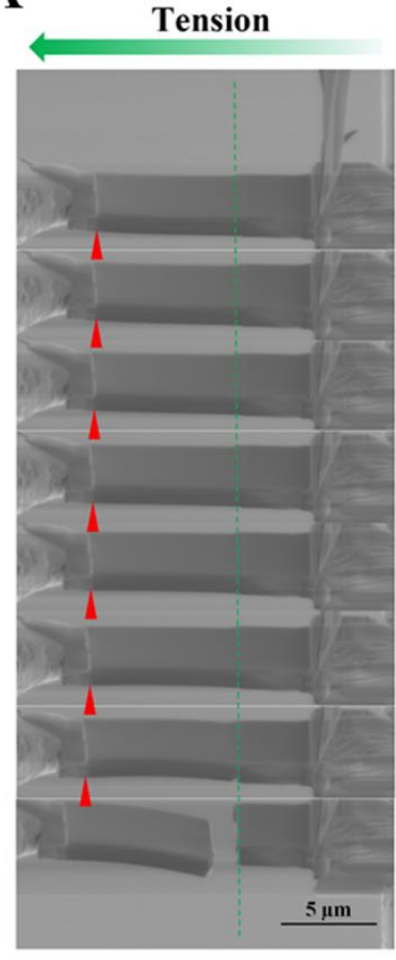

B

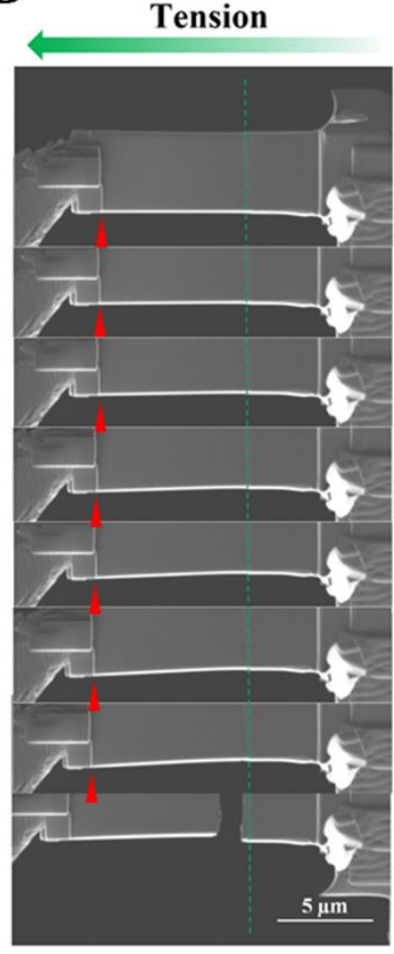

C

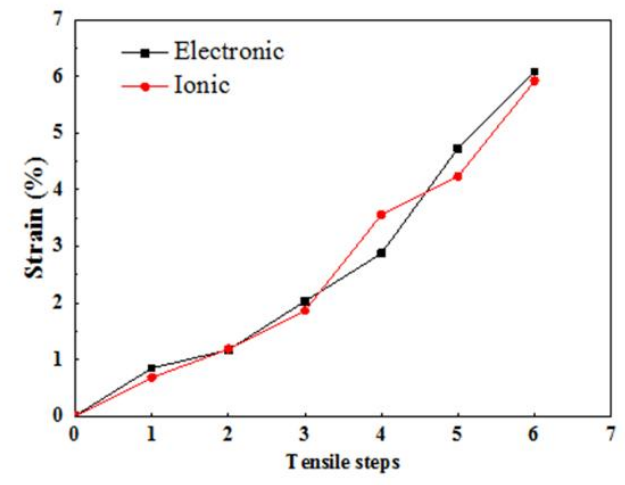

D

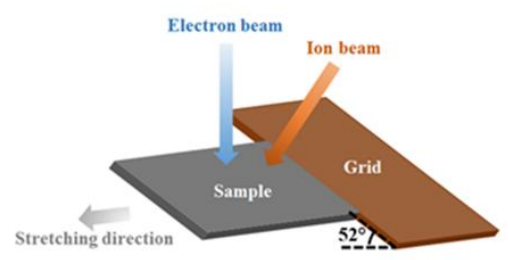


Fig. 6 Stretching process of a raw CF/epoxy composite sample observed by SEM with two series(A) Electron and (B) Ion images; (C) Strain-step curves during the stretching process, data extracted from two series of images; (D) Sketch of the global sample position, with regard to the stretching direction and the two beam sources.

Fig. 6(A) presents SEM images where an increasing tensile displacement is applied to an interface until the failure is reached. The green arrows on the top indicate the tensile direction, and the CF/epoxy interface is pointed out by a green line. It is obvious that the CF part is thicker than the matrix, which is caused by the milling process: Since CFs are much harder than polymers, the CF cannot achieve the same thickness as the matrix with the same milling conditions. However, it is found that the interface position remains at the same position during the stretching process, which indicates the traverse strain of the CF can be negligible compared with the polymer domain due to its much higher modulus.

As a method of evaluation and confirmation of the tensile displacement, ion beam images were also acquired during testing along with electron images, as shown in Fig. 6(B). For each tensile stepwise, the error in displacement can be effectively reduced by measuring and comparing the two series of images. Fig. 6(D) shows the sample position: the angle between the electron beam and the sample surface plane is $38^{\circ}$ and the angle between the ion beam and the sample surface plane is $90^{\circ}$. The stretching direction is perpendicular to the plane generated by the two beam sources.

The apparent strain is defined by the change in the length of the segment between the interface and the deposited Pt. As shown in Fig. 6(C), the curves about the strain-stretching steps in the two series of images are extracted. During the stretching process, the manipulator moves by steps of $200 \mathrm{~nm}$. However, in the first stage, the strain is not increased due to the tiny bending existing in the manipulator. The two curves are almost overlapped with little difference. Hence, the strain measurement can be conducted with either type of image which exhibit a clear CF/epoxy interface. 

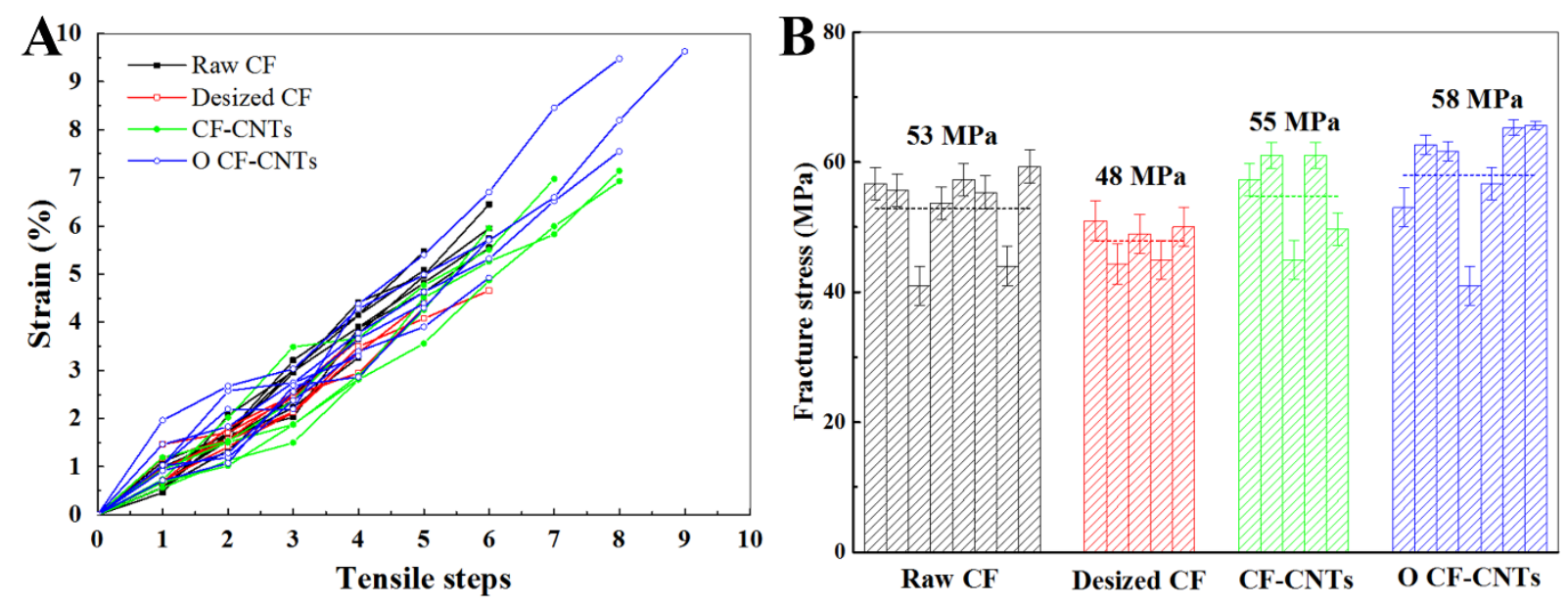

Fig. 7 (A) Displacement-tensile step plot of stretching samples extracted from ionic images. The black, red, green and blue lines are the results from the raw CF/epoxy, desized CF/epoxy, CNT-CFs/epoxy and oxidized CNT-CFs/epoxy, respectively. (B) Fracture strengths of the raw CF/epoxy, desized CF/epoxy, CNT-CF/epoxy and oxidized CNT-CF/epoxy.

The displacement is measured by either ionic or electron images acquired during each tensile step, as shown in Fig. 7(A). The strain of all the curves increases linearly during the stretching. The curves have a similar slope since the major strain is localized on the epoxy part with almost the same geometry. The small discrepancy in the curves is due to the flurry boundary in some images (the green lines in Fig. 6(A) and (B)). According to the measured results, the failure step happens between steps four and nine. The fracture of raw CF/epoxy interface mostly happens in step six, leading to an average strain of $5.14 \%$. The desized $\mathrm{CF} / \mathrm{epoxy}$ tend to break at a lower step, mostly at the fourth and fifth step, leading to an average strain of about $4.15 \%$. After grafting CNTs, the interaction between CF-CNTs and epoxy recover and the fracture mostly happens in sixth, leading to an average strain of $5.59 \%$. By oxidation treatment, the interaction between oxidized CF-CNTs and epoxy matrix further increases. The breaking point tends to happen at a higher step. Even for two samples of oxidized CF-CNTs/epoxy composite, the fracture happens at the connection point or in the epoxy matrix, rather than at the interface, which indicates that the interfacial strength between oxidized CF-CNTs and epoxy is larger than the fracture strength of epoxy matrix.

Since the stress-strain values of pure epoxy can be easily acquired by tensile test (as shown in Fig. S7, the interfacial strength between CFs and epoxy can be estimated by fitting the corresponding strain in the stress-strain curves, as shown in Fig. 7(B). The fracture strength of epoxy is $66.5 \mathrm{MPa}$. The average strain of oxidized CF-CNTs/epoxy is $6.82 \%$ before failure, corresponding to $58 \mathrm{MPa}$ in the stress-strain curves. However, since several 
samples broke in the matrix part, the actual interfacial strength of oxidized CF-CNTs/epoxy is possibly larger than $58 \mathrm{MPa}$. By using the same method, the interfacial strength of raw CF/epoxy, CF-CNT/epoxy and disized CF/epoxy are 53, 55 and $48 \mathrm{MPa}$, respectively. These values are close to the values reported by other groups [32]. There are three aspects which results in the limitation of improvement over desized CF/epoxy composites. A) as we learnt from figure $7 \mathrm{~B}$, the variation of calculated tensile strength in desized $\mathrm{CF} /$ epoxy composites is much smaller than three other composites. In intrinsic $\mathrm{CF}, \mathrm{CNT}-\mathrm{CF}$ and oxidized CNT-CF /epoxy composites, there always exist low values at the same level as the desized CF/epoxy, which was due to the error place. But in the final results, due to the limitation of tested samples, these values were also included to calculate the average value for each composite. This could lead to the reduce of the improvement. B) according to the XPS results in Figure $\mathrm{S} 4$, there had a small O peak in the spectrum of desized CF. Even though the sizing layer has been removed by heating the $\mathrm{CFs}$ in an argon atmosphere, the inevitable oxidation of the $\mathrm{CF}$ surface has happened, which could enhance the interfacial adhesion due to the existence of oxygen-containing groups. C) For the failure behavior, there had two samples failure in the epoxy part for the oxidized CNT-CF/epoxy composite. However, we have used the ultimate stress of epoxy to calculate the bond strength of the oxidized CNT-CF/epoxy composite. The real value should be higher than that. All three aspects lead to reducing the difference between them.

To understand the function of the CNT layer on the CF surface, the STEM combined with EDX has been employed to study the CF/Epoxy composite interface. It is suitable for acquiring high-resolution images with a detailed elemental information and quantitative analyses on the interphase composition. It has been successfully adopted in various fields [3336]. Four TEM lamellas were prepared by FIB (Fig. S8). The CF orientation is parallel to the lamella plane. In four images, the dark part is the CF in which the thickness is larger than the one of epoxy because the ion polishing is difficult down to the ideal thickness due to a higher hardness of CF compared to the epoxy matrix. Furthermore, since CF, CNTs and epoxy resin are carbon-based materials, the contrast difference is weak in bright field. It is preferable HAADF detector in STEM mode, which is known as Z-contrast configuration. It has two major advantages: one is that small differences in the average atomic number or thickness of the material can be observed with a higher contrast difference in the dark field image; the other is that the interested region can be focused to a very small point ( $\# 0,1 \mathrm{~nm}$ in diameter), which helps to acquire high resolution EDX mapping. Fig. 8 shows two STEM HAADF 
images of raw CF/epoxy and CF-CNT/epoxy, respectively. For the raw CF/epoxy (Fig. 8A), the bright region corresponds to the $\mathrm{CF}$ part with a larger thickness than the epoxy part while the dark part is the pure epoxy. The interface in between is the obvious boundary. CFCNT/epoxy is presented in Fig. 8B. A tubular structure can be clearly observed by STEM under high resolution. After grafting CNTs on a CF surface, the epoxy matrix can immerse the CNT layer and wet the CF surface completely without creating voids in the interface region. The CNTs are dispersed in the matrix homogeneously. The average thickness of the CNT layer is around $440 \mathrm{~nm}$, which has already been confirmed by SEM image. The bright spots in the matrix domain should be the catalyst used for the CNT growth.

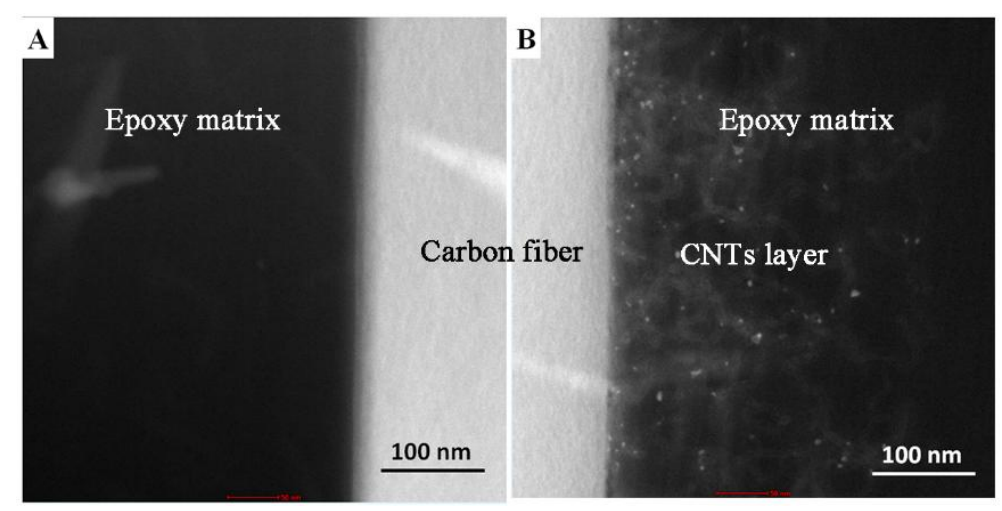

Fig. 8 STEM Z-contrast (HAADF) image showing the interface region of the CF and epoxy: (A) raw CF/epoxy and (B) CNT-CF/epoxy interfaces.

Fig. 9(A) presents a STEM image of raw CF/epoxy interface. The green rectangle corresponds to the region selected for EDX analysis where three elements -- oxygen, carbon and chlorine -- were investigated. Chlorine exists in the sizing layer but has migrated to the epoxy domain and has aggregated at the interface. For oxygen, there also exists an aggregation at the interface, indicating that the oxygen-containing groups have a higher density than in the epoxy matrix. For carbon, the aggregation in the CF domain is obvious. 

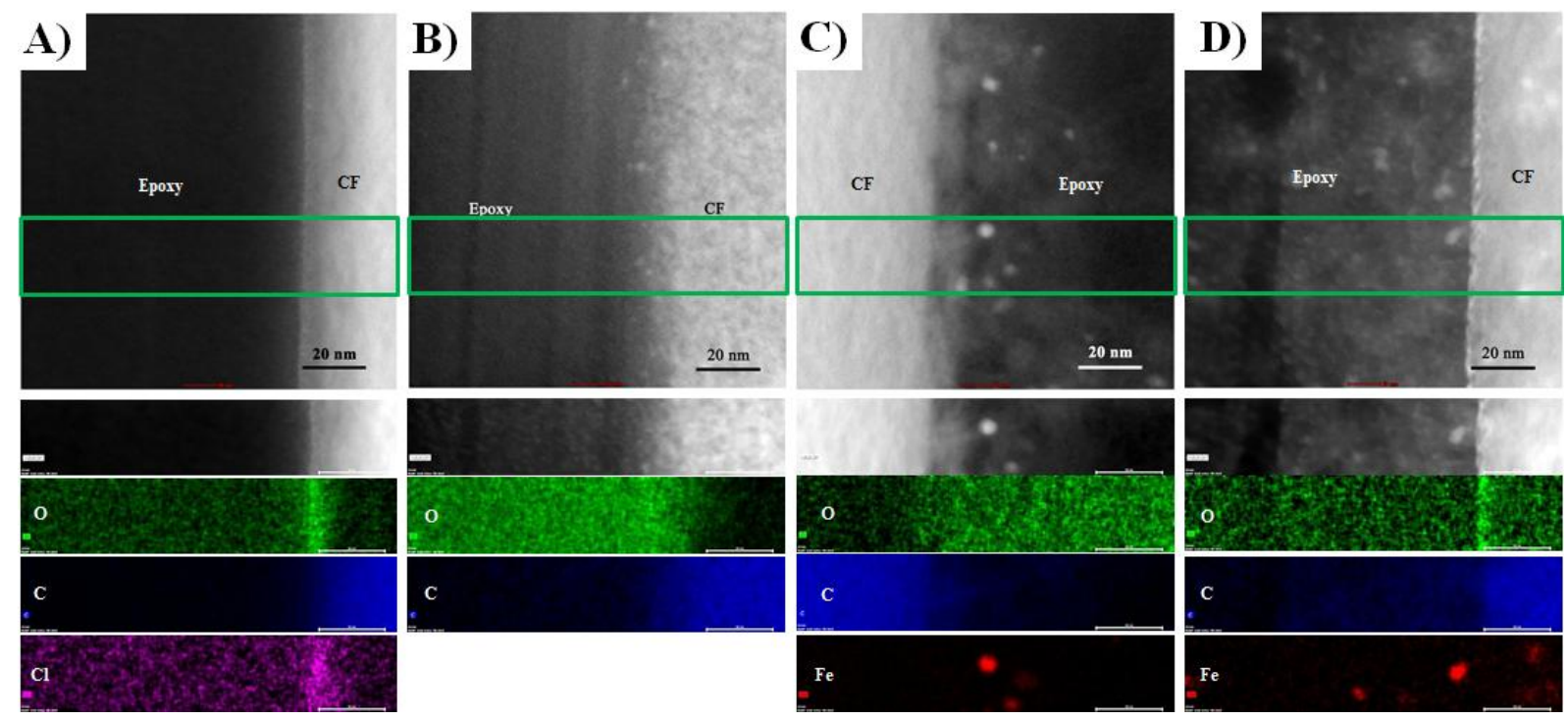

Fig. 9 High magnification STEM Z-contrast (HAADF) image showing a CF perpendicular to the epoxy foil prepared by FIB: Interfaces of (A) Raw CF/epoxy, (B) Desized CF/epoxy, (C) CNT-CF/epoxy and (D) Modified CNT-CF/epoxy, respectively. The regions marked out by the green rectangle were analyzed by EDX, the elements were marked out by different colors, green for oxygen, blue for carbon, pink for chlorine and red for iron, respectively.

Fig. 9(B) shows a STEM image of desized CF/epoxy interface. After the removal of the sizing layer, there is no aggregation in the interface part. From the CF to the epoxy domains, the element presence changes gradually both for carbon and oxygen. Compared with raw $\mathrm{CF} /$ epoxy composite, the interface is more blurred in desized CF/epoxy.

Fig. 9(C) and (D) correspond to the observation of CF-CNT/epoxy and modified CFCNT/epoxy composites, respectively. The CNT layers are distributed homogeneously on the $\mathrm{CF}$ surfaces. The bright spots near the interface correspond to the heavier iron catalyst particles, which is confirmed by EDX. The CNT layer morphology can be figured out in the epoxy matrix. In the case of the CF-CNT/epoxy interface, the elements also change gradually. However, in the modified CF-CNT/epoxy interface, I find there an oxygen aggregation. As far as carbon is concerned, there is no element aggregation layer.

Grafting a layer of CNTs on the surface of CF is a common method to modify the interaction between the polymer matrix and CFs. The effect of reinforcement is obvious since the CNT layer can greatly increase the contact area at the interface. Moreover, the CNTs, with their perpendicular arrangement, can insert in the matrix part and further increase the interfacial strength. The CNT layer can also increase the conductivity of the entire composites. 
After removing the sizing layer, the interaction between the CFs and the epoxy matrix is greatly weakened due to the decrease of chemical bonds. After grafting CNTs on the surface, the increased interfacial strength is obvious compared to the case of desized CF/epoxy composites, since CNTs can largely increase the contact area between matrix and CF. Furthermore, the CNT layer, with its mechanical properties, could enhance the surrounded matrix. The oxidized CF-CNT/epoxy composite presents the best interfacial strength of the four composites. The oxidized CF-CNTs are fabricated by heating the sample at $400{ }^{\circ} \mathrm{C}$ for $4 \mathrm{~min}$ to increase the oxygen-containing groups on the surface. The obvious aggregation of the oxygen at the interface can largely increase the interfacial strength between the CFs and the epoxy matrix. The same reason could be used to explain the interaction between raw $\mathrm{CFs}$, which contains a sizing layer to increase the interaction between $\mathrm{CF}$, and epoxy matrix. As we have mentioned before, increasing the surface roughness and depositing a transition layer are two major methods to improve the interfacial properties. Here, oxidized CF-CNTs combine both methods, i.e. grafting CNTs increases the surface roughness and introduces oxygen-containing groups to increase the chemical bonding, which leads to the best interfacial strength of the four types of composites.

\section{CONCLUSION}

In this work, an in-situ tensile test was conducted in an SEM to measure the interfacial strength between carbon fibres and the epoxy matrix. Four types of CF reinforced epoxy composites - raw CF, desized CF, CNTs-CF and oxidized CNTs-CF-have been investigated. Based on the results, it was found that grafting a CNT layer on the CF surface can modify the interfacial properties and reinforce the epoxy matrix surrounding the CF. After further oxidation of CF-CNTs, the interfacial strength can be further increased. Through a STEM and EDX analysis, it was found that the interaction between oxygen-containing groups and epoxy was the crucial factor in determining the interfacial strength. This knowledge can be used to guide the modification of other types of reinforcement to fabricate composites with excellent mechanical properties.

\section{SUPPORTING INFORMATION}

This material includes the tensile test result of pure epoxy, XPS analysis of four types of CF, TGA/DTG curve of CF-CNTs, simulation work, SEM images of desized CF and oxidized CF-CNTs, and TEM images of lamellae. 


\section{ACKNOWLEDGMENTS}

This work was carried out within the MATMECA consortium and supported by the ANR under contract number ANR-10-EQPX-37. It has benefited from the facilities of the Laboratory MSSMat (UMR CNRS 8579), CentraleSupélec, France. We thank Dr. L. WANG and Dr. Y. CHEN for the SEM sample preparation. Yu LIU thanks China Scholarship Council for the fellowship.

\section{REFERENCES}

[1] Y. Gan, Effect of Interface Structure on Mechanical Properties of Advanced Composite Materials, International Journal of Molecular Sciences 10(12) (2009) 5115.

[2] J. Schultz, L. Lavielle, Interfacial Properties of Carbon Fiber-Epoxy Matrix Composites, Inverse Gas Chromatography, American Chemical Society1989, pp. 185-202.

[3] J. George, M. Sreekala, S. Thomas, A review on interface modification and characterization of natural fiber reinforced plastic composites, Polymer Engineering \& Science 41(9) (2001) 1471-1485.

[4] J. Schultz, L. Lavielle, C. Martin, The role of the interface in carbon fibre-epoxy composites, The Journal of Adhesion 23(1) (1987) 45-60.

[5] D. He, B. Fan, H. Zhao, X. Lu, M. Yang, Y. Liu, J. Bai, Design of Electrically Conductive Structural Composites by Modulating Aligned CVD-Grown Carbon Nanotube Length on Glass Fibers, ACS Applied Materials \& Interfaces 9(3) (2017) 2948-2958.

[6] E. Totry, J.M. Molina-Aldareguía, C. González, J. Llorca, Effect of fiber, matrix and interface properties on the in-plane shear deformation of carbon-fiber reinforced composites, Composites Science and Technology 70(6) (2010) 970-980.

[7] S.-J. Park, M.-H. Kim, J.-R. Lee, S. Choi, Effect of Fiber-Polymer Interactions on Fracture Toughness Behavior of Carbon Fiber-Reinforced Epoxy Matrix Composites, Journal of Colloid and Interface Science 228(2) (2000) 287-291.

[8] I.K. Ismail, M.D. Vangsness, On the improvement of carbon fiber/matrix adhesion, Carbon 26(5) (1988) 749-751.

[9] Z. Dai, F. Shi, B. Zhang, M. Li, Z. Zhang, Effect of sizing on carbon fiber surface properties and fibers/epoxy interfacial adhesion, Applied Surface Science 257(15) (2011) 6980-6985.

[10] R.L. Zhang, Y.D. Huang, D. Su, L. Liu, Y.R. Tang, Influence of sizing molecular weight on the properties of carbon fibers and its composites, Materials \& Design 34 (2012) 649-654. 
[11] R. Sager, P. Klein, D. Lagoudas, Q. Zhang, J. Liu, L. Dai, J. Baur, Effect of carbon nanotubes on the interfacial shear strength of T650 carbon fiber in an epoxy matrix, Composites Science and Technology 69(7) (2009) 898-904.

[12] H. Qian, A. Bismarck, E.S. Greenhalgh, G. Kalinka, M.S.P. Shaffer, Hierarchical Composites Reinforced with Carbon Nanotube Grafted Fibers: The Potential Assessed at the Single Fiber Level, Chemistry of Materials 20(5) (2008) 1862-1869.

[13] X. He, F. Zhang, R. Wang, W. Liu, Preparation of a carbon nanotube/carbon fiber multiscale reinforcement by grafting multi-walled carbon nanotubes onto the fibers, Carbon $45(13)$ (2007) 2559-2563.

[14] A. Warrier, A. Godara, O. Rochez, L. Mezzo, F. Luizi, L. Gorbatikh, S.V. Lomov, A.W. VanVuure, I. Verpoest, The effect of adding carbon nanotubes to glass/epoxy composites in the fibre sizing and/or the matrix, Composites Part A: Applied Science and Manufacturing 41(4) (2010) 532-538.

[15] A.H. Barber, Q. Zhao, H.D. Wagner, C.A. Baillie, Characterization of E-glasspolypropylene interfaces using carbon nanotubes as strain sensors, Composites Science and Technology 64(13-14) (2004) 1915-1919.

[16] E. Bekyarova, E.T. Thostenson, A. Yu, M.E. Itkis, D. Fakhrutdinov, T.-W. Chou, R.C. Haddon, Functionalized Single-Walled Carbon Nanotubes for Carbon Fiber-Epoxy Composites, The Journal of Physical Chemistry C 111(48) (2007) 17865-17871.

[17] M. Li, Y. Gu, Y. Liu, Y. Li, Z. Zhang, Interfacial improvement of carbon fiber/epoxy composites using a simple process for depositing commercially functionalized carbon nanotubes on the fibers, Carbon 52 (2013) 109-121.

[18] z.g. zhao, L. CI, H. Cheng, J. Bai, Growth of multi-walled carbon nanotube of different morphologies on carbon fibres by floating catalyst method, Carbon 43(3) (2004).

[19] L. CI, J. Bai, Direct growth of aligned carbon nanotubes on the surface of ceramic fibers, Carbon 43(4) (2005).

[20] J. Zhu, J. Kim, H. Peng, J.L. Margrave, V.N. Khabashesku, E.V. Barrera, Improving the Dispersion and Integration of Single-Walled Carbon Nanotubes in Epoxy Composites through Functionalization, Nano Letters 3(8) (2003) 1107-1113.

[21] E. Bekyarova, E.T. Thostenson, A. Yu, H. Kim, J. Gao, J. Tang, H.T. Hahn, T.W. Chou, M.E. Itkis, R.C. Haddon, Multiscale Carbon Nanotube-Carbon Fiber Reinforcement for Advanced Epoxy Composites, Langmuir 23(7) (2007) 3970-3974. 
[22] V.P. Veedu, A. Cao, X. Li, K. Ma, C. Soldano, S. Kar, P.M. Ajayan, M.N. GhasemiNejhad, Multifunctional composites using reinforced laminae with carbon-nanotube forests, Nature materials 5(6) (2006) 457-462.

[23] A. Godara, L. Mezzo, F. Luizi, A. Warrier, S.V. Lomov, A.W. van Vuure, L. Gorbatikh, P. Moldenaers, I. Verpoest, Influence of carbon nanotube reinforcement on the processing and the mechanical behaviour of carbon fiber/epoxy composites, Carbon 47(12) (2009) 2914-2923. [24] L. Gao, T.-W. Chou, E.T. Thostenson, Z. Zhang, A comparative study of damage sensing in fiber composites using uniformly and non-uniformly dispersed carbon nanotubes, Carbon 48(13) (2010) 3788-3794.

[25] A.N. Netravali, R.B. Henstenburg, S.L. Phoenix, P. Schwartz, Interfacial shear strength studies using the single-filament-composite test. I: Experiments on graphite fibers in epoxy, Polymer Composites 10(4) (1989) 226-241.

[26] C. DiFrancia, T.C. Ward, R.O. Claus, The single-fibre pull-out test. 1: Review and interpretation, Composites Part A: Applied Science and Manufacturing 27(8) (1996) 597-612. [27] B. Miller, P. Muri, L. Rebenfeld, A microbond method for determination of the shear strength of a fiber/resin interface, Composites Science and Technology 28(1) (1987) 17-32. [28] A. Godara, L. Gorbatikh, G. Kalinka, A. Warrier, O. Rochez, L. Mezzo, F. Luizi, A. Van Vuure, S. Lomov, I. Verpoest, Interfacial shear strength of a glass fiber/epoxy bonding in composites modified with carbon nanotubes, Composites Science and Technology 70(9) (2010) 1346-1352.

[29] K.R. Totten, B. Kutub, L.A. Carlsson, In situ determination of the fiber-matrix interface tensile strength, Journal of Composite Materials 50(5) (2016) 589-599.

[30] J. Bai, Procede de synthese de nanotubes de carbone sur materiaux micrometriques longs et particulaires, Google Patents, 2010.

[31] Y. Liu, A.-L. Hamon, P. Haghi-Ashtiani, T. Reiss, B. Fan, D. He, J. Bai, Quantitative Study of Interface/Interphase in Epoxy/Graphene-Based Nanocomposites by Combining STEM and EELS, ACS Applied Materials \& Interfaces 8(49) (2016) 34151-34158.

[32] E. Mäder, S. Melcher, J.-W. Liu, S.-L. Gao, A. Bianchi, S. Zherlitsyn, J. Wosnitza, Adhesion of PBO fiber in epoxy composites, Journal of materials science 42(19) (2007) 80478052.

[33] W. Zhou, J. Lee, J. Nanda, S.T. Pantelides, S.J. Pennycook, J.-C. Idrobo, Atomically localized plasmon enhancement in monolayer graphene, Nature nanotechnology 7(3) (2012) 161-165.

[34] C.B. Carter, D.B. Williams, Transmission electron microscopy, Springer-Verlag US2009. 
[35] Q. Wu, M. Li, Y. Gu, Y. Li, Z. Zhang, Nano-analysis on the structure and chemical composition of the interphase region in carbon fiber composite, Composites Part A: Applied Science and Manufacturing 56 (2014) 143-149.

[36] S. Yang, X. Feng, L. Wang, K. Tang, J. Maier, K. Müllen, Graphene - Based Nanosheets with a Sandwich Structure, Angewandte Chemie International Edition 49(28) (2010) 47954799. 